\section{Application of a New Surge Arrester Model in Protection Studies Concerning Switching Surges}

\section{Popov, L. van der Sluis, G.C. Paap}

Author Affiliation: Delft University of Technology, The Netherlands.

Abstract: Surge arresters, which are used to protect transformers against overvoltages, are an important part of the power system. Overvoltages occur because of switching operations of nearby circuit breakers or as a result of lightning strokes. The behavior of the surge arrester during an overvoltage occurrence depends on the amplitude and the shape of the surge. Therefore, it is important to have an understanding of the behavior of the surge arrester when it is stressed by overvoltages with different shapes and amplitudes.

In this letter, the application of a simplified model of a surge arrester is presented. The behavior of the arrester based on its measured volt-ampere characteristic is examined according to the ANSI/IEEE C62.11-1993 standard. The residual voltage of the arrester is calculated for three different current impulses: $8 / 20 \mu \mathrm{s}, 30 / 60 \mu \mathrm{s}$, and an impulse with a $0.5 \mu$ s front-of-wave. The application of the model is presented when it is used for protecting a distribution transformer exposed to voltage escalation and to low-frequency surges.

Introduction: As a result of switching in a part of a system or because of occurrence of lightning strokes in high-voltage networks, high overvoltages can occur that sometimes can be several times greater than the nominal voltage of the system. An overvoltage is an unwanted phenomenon that can cause deterioration of the insulation of the equipment and therefore affects the proper functioning of the system in general.

The analysis of steep-fronted overvoltages is an important item for the insulation coordination. Therefore, R-C circuits like surge suppressors and surge arresters are applied to protect against high overvoltages.

In general, a surge arrester reacts only when its predetermined threshold value is surpassed, and when the amplitude of the impulse tends to increase further, the arrester will limit its value. A major task of the arrester is to protect the equipment against overvoltages that occur during switching operations or during lightning impulses. The application of an $\mathrm{R}-\mathrm{C}$ circuit reduces the steepness of the surge. This leads to a decrease of the frequency of the transient recovery voltage (TRV) and prevents the occurrence of reignition overvoltages. R-C circuits are applied to protect reactive loads such as motors and transformers. The disadvantage is that their operation is influenced by the ambient temperature and by the environmental pollution. The result is a nonoptimal operation of the R-C circuit.

This letter analyses only the application of surge arresters for protecting equipment. A simplified surge arrester model is presented with parameters based on manufacturer data and the residual voltages are studied. The application of the arrester for protection of a transformer against switching surges is also investigated.

Surge Arrester Model: The surge arrester model does not take into account the temperature dependency of the nonlinear resistance. This is in fact only important for small currents, which are not observed here. The capacitance of the arrester is considered constant. Also, because of the lack of data, the U-I hysteresis is not taken into account. The resulting surge arresters model is shown in Figure 1.

The determination of the surge arrester parameters is described in detail in [1].

According to the IEEE/ANSI C62.11-1993 standard, the maximum value of the residual voltages should be calculated for current impulses with an amplitude of $10 \mathrm{kA}$ and steepnesses of $8 / 20 \mu \mathrm{s}, 0.5 / 3 \mu \mathrm{s}$, and $30 / 60 \mu \mathrm{s}$. The results of the applied model for different current impulses are shown in Figures 2 through 4.

The residual voltages provided by the manufacturer are shown in Table 1. The values for the residual voltages V10 kA are $44 \mathrm{kV}$ and 51.6 $\mathrm{kV}$ when the surge arrester is excited by a current impulse $8 / 20 \mu \mathrm{s}$ and by a current impulse with a front-of-wave $0.5 \mu \mathrm{s}$, respectively. The calculated values by our model are $43.2 \mathrm{kV}$ and $51.8 \mathrm{kV}$, respectively.
The measured value of the residual voltage V500 A with a current impulse $30 / 60 \mu$ s is $32.3 \mathrm{kV}$ and the computed value is $31.7 \mathrm{kV}$.

Note that for very steep surges, the model results in higher residual voltages than those specified by the manufacturer. Therefore, for very steep surges the U-I hysteresis of the transformer must also be taken into account [2].

Practical Application of the Model: The application of the model can be illustrated by the circuit shown in Figure 5. An unloaded transformer is switched off by a vacuum circuit breaker. The circuit breaker

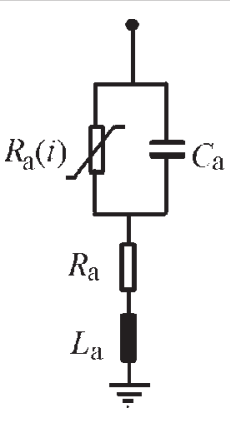

Figure 1. A simplified surge arrester model
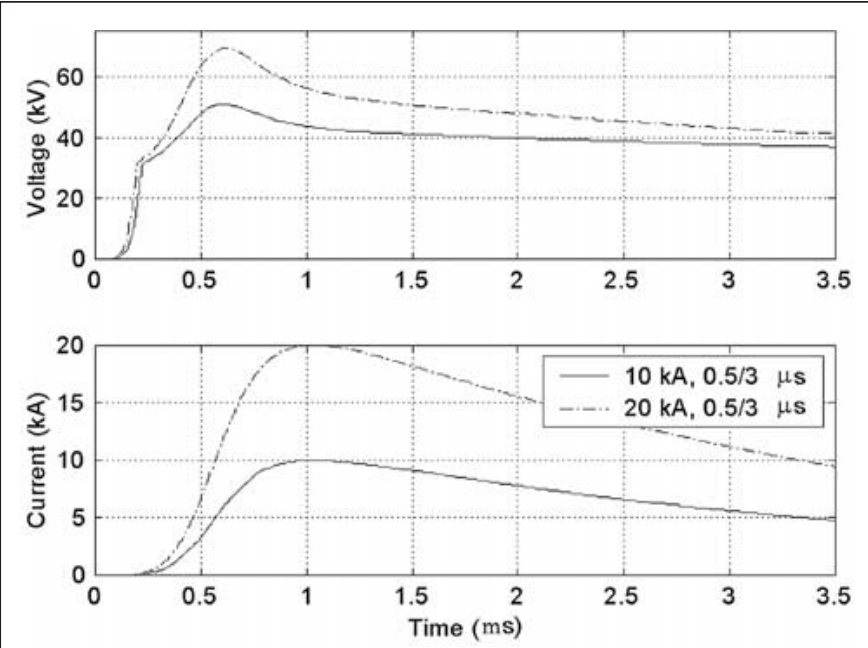

Figure 2. Residual voltage of the surge arrester excited by a current impulse $0.5 / 3 \mu s$
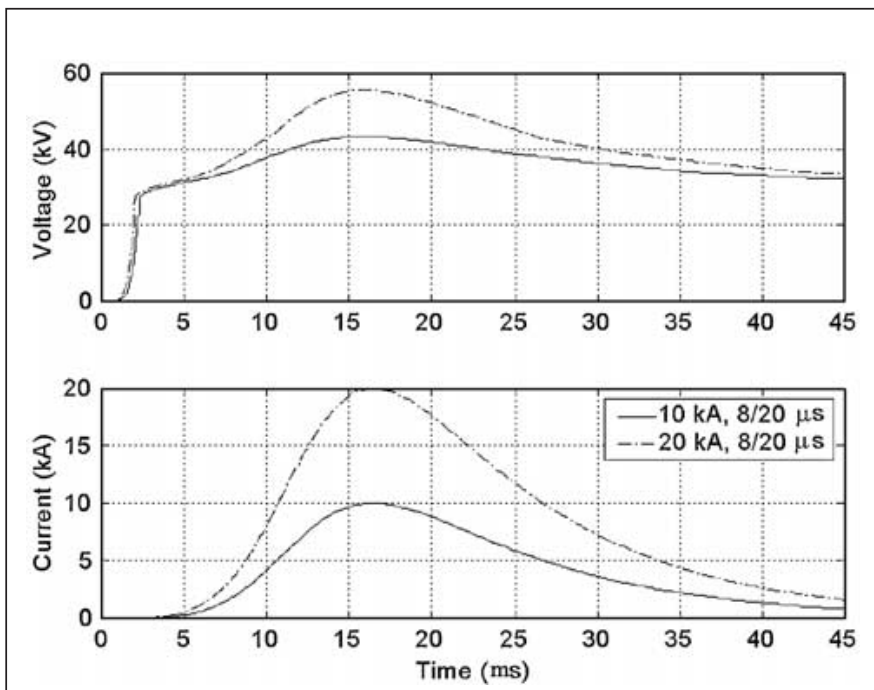

Figure 3. Residual voltage of the surge arrester excited by a current impulse $8 / 20 \mu s$ 


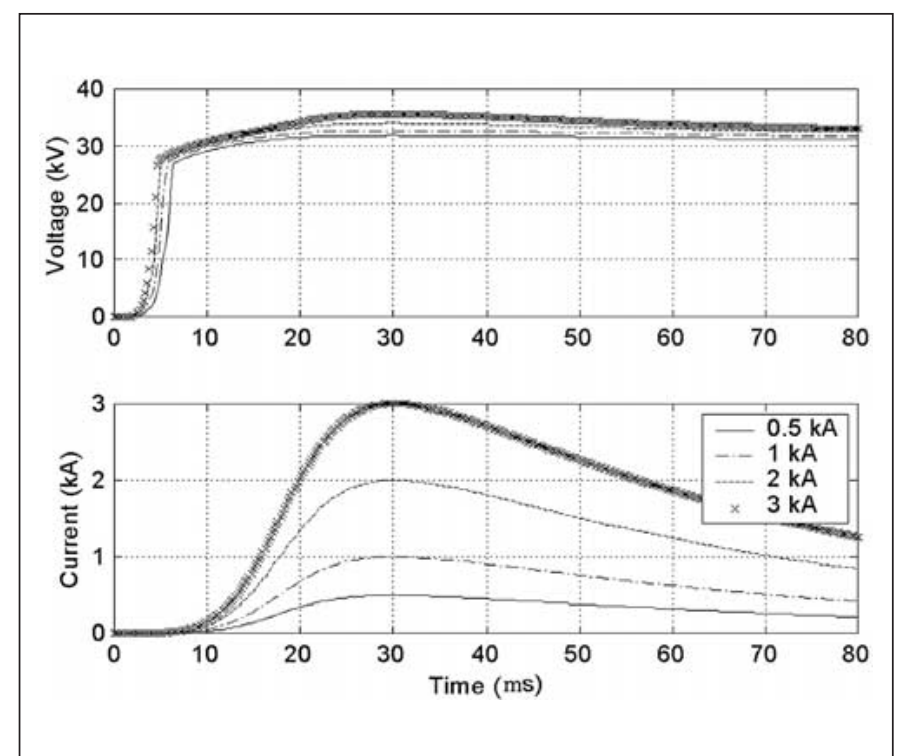

Figure 4. Residual voltage of the surge arrester excited by a current impulse $30 / 60 \mu s$

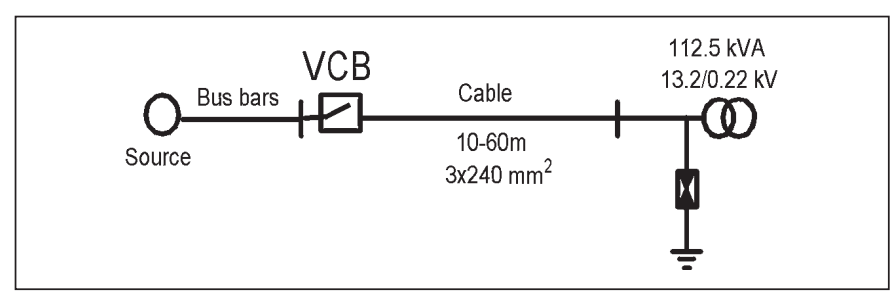

Figure 5. Circuit for practical analysis of the transients

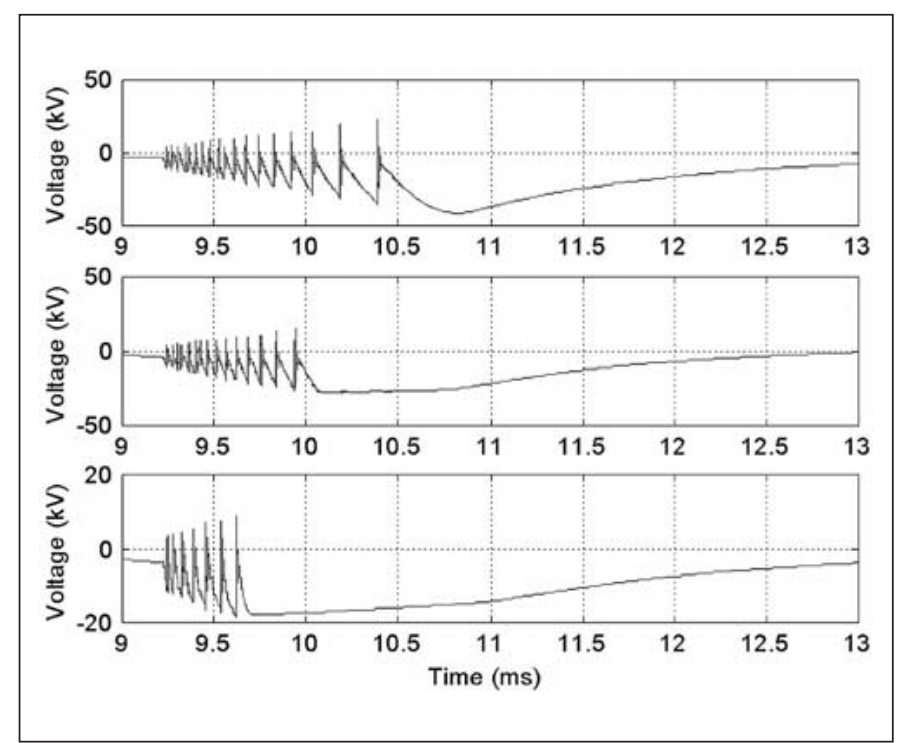

Figure 6. Reignition overvoltage at a transformer terminal; upper trace: no protection; middle trace: arresters installed between phase and ground; lower trace: arresters installed between phase and ground and between phases

is connected to the transformer by a feeder cable with a length of $30 \mathrm{~m}$. For all system components, frequency dependent models are used [3].

The calculations were done with three surge arresters connected in each phase to ground, and with six surge arresters connected phase to ground and between phases.

Figure 6 shows the reignition overvoltage in one phase when no protection is applied and when the protection is provided by surge arresters installed between each phase and ground (first case), and between each phase and ground and between phases (second case).

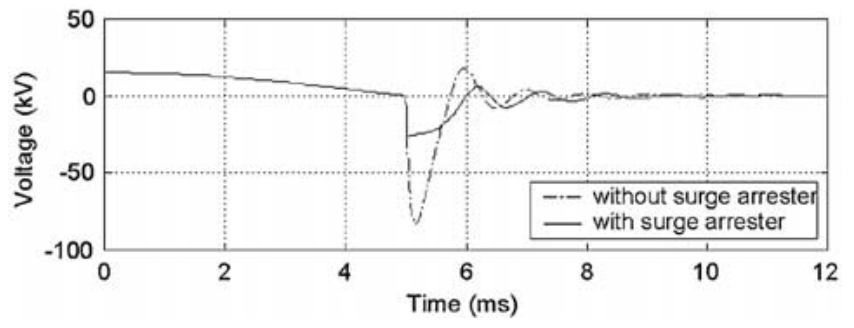

Figure 7. Application of the model against slow surges (no reignition)

Table 1. Surge arrester data

\begin{tabular}{|l|l|}
\hline Nominal voltage $(\mathrm{kV})$ & 12 \\
\hline MCOV $(\mathrm{kV}$ rms) & 10 \\
\hline V10 kA - current impulse $8 / 20 \mu \mathrm{s}(\mathrm{kV})$ & 44 \\
\hline V10 kA - current impulse $0.5 \mu \mathrm{s},(\mathrm{kV})$ & 51.6 \\
\hline V500 A - current impulse $30 / 60 \mu \mathrm{s}(\mathrm{kV})$ & 32.3 \\
\hline Energy absorption $(\mathrm{kJ} / \mathrm{kV})$ & 4.3 \\
\hline
\end{tabular}

The investigation shows that when using three surge arresters (the first case), the phase to ground overvoltage is limited only to the protection level of the surge arrester while the overvoltage between phases can still remain high. The second case shows that both voltages, phase to ground and phase to phase, are significantly reduced. Another observation is that the duration of the reignition is shorter than in the configuration with three arresters.

The application of the model to slow front surges like switching overvoltages when no reignition takes place is shown in Figure 7. The unloaded transformer [4] is de-energized and because of the residual flux and hysteresis, high overvoltages occur. The arrester surges the overvoltage below $30 \mathrm{kV}$.

Conclusion: In this letter, the application of a new simplified arrester model is introduced based on an available measured U-I characteristic of an arrester. The model is appropriate for studies where the current impulses do not reach very high values, such as surges produced by a reignition in the circuit breaker.

The application of the arrester is demonstrated on a practical example where an unloaded transformer is switched off by a vacuum circuit breaker.

References:

[1] M. Popov, L. van der Sluis, and G.C. Paap, "Investigation of the circuit breaker reignition overvoltages caused by no-load transformer switching surges," European Trans. Electric Power (ETEP), vol. 11, no. 6, pp. 413-422, Nov./Dec. 2001.

[2] IEEE WG 3.4.11, "Modelling of metal oxide surge arresters," IEEE Trans. Power Delivery, vol. 7, pp. 302-309, Jan. 1992.

[3] M. Popov and L. van der Sluis, "Improved calculations for no-load transformer switching surges," IEEE Trans. Power Delivery, vol. 16, pp. 401-408, July 2001.

[4] M. Popov, L. van der Sluis, G.C. Paap, and P.H. Schavemaker, "On a hysteresis model for transient analysis," IEEE Power Eng. Rev., vol. 20, pp. 53-54, May 2000.

Copyright Statement: ISSN 0282-1724/02/\$17.00 @ 2002 IEEE. Manuscript received 17 June 2002. This paper is published herein in its entirety. 